\title{
Fakten, Fakten, Fakten ...
}

\section{Liebe Leserinnen und Leser,}

der Begriff „Evidence-based Management“ wird bislang in keinem Controlling-Lehrbuch erwähnt und ist wohl auch vielen von Ihnen noch unbekannt. Gleichwohl hat der aus den Vereinigten Staaten kommende Ansatz eine hohe Relevanz für jeden Controller. Wie der Name schon nahelegt, fordern die Vertreter dieser aus der Medizin kommenden Denkrichtung, Entscheidungen konsequent nur auf wirklich belastbaren Erkenntnissen und - soweit möglich - empirischer Evidenz zu basieren. Fakten, Fakten, Fakten ... geht einem unwillkürlich durch den Sinn, und damit ist die Brücke zum Controlling auch schon geschlagen. Wer als Controller die Rationalität der Unternehmensführung sichern möchte und damit auch in Entscheidungsprozessen auf eine möglichst belastbare Datenbasis und analytisches Denken abzielt, wird sich mit dem Gedanken, der hinter Evidence-based Management steht, schnell anfreunden können. Da die Umsetzung des hehren Zieles in der Praxis aber hinreichend schwer ist und wohl gelegentlich auch an Grenzen stößt, wollen wir im vorliegenden Heft der Frage nachgehen, ob die populäre Strömung auch für Controller verwertbare Techniken und Erfahrungen enthält.

Zunächst möchten wir jedoch den Grundgedanken von Evidence-based Management noch ein wenig veranschaulichen. Nehmen wir ein Beispiel: Die meisten Unternehmen entlohnen ihr Management auf der Basis hoher variabler Gehaltsbestandteile. Dabei gibt es kaum belastbare empirische Evidenz dafür, dass damit auch wirklich bessere Entscheidungen der Führungsmannschaft einhergehen. Dennoch wird die gängige Praxis in aller Regel nicht hinterfragt. Boni für die Führungsmannschaft gibt es eben, die Konkurrenz macht es schließlich genauso. Und in der Tat zeigt ein Blick in die Literatur, dass Boni etwa für einzeln agierende Verkäufer durchaus Sinn machen können. Wenn aber die engen Voraussetzungen für den produktiven Einsatz leistungsabhängiger Gehaltsbestandteile - wie insbesondere ihre Messbarkeit und individuelle Zuordenbarkeit - nicht gegeben sind, dominieren schnell dysfunktionale Nebenwirkungen. Und wenn Managern nur lange genug vermittelt wird, dass sie im Kern opportunistisch sind und nur für die Boni arbeiten, ist zudem die Wahrscheinlichkeit hoch, dass sich diese Prophezeiung eines Tages auch in der Unternehmenskultur manifestiert. Aus der

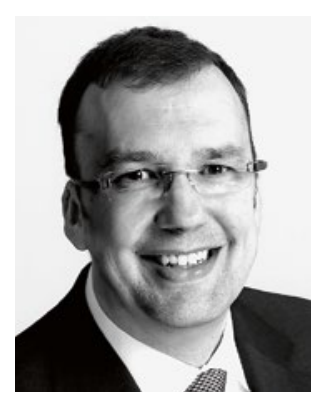

Utz Schäffer

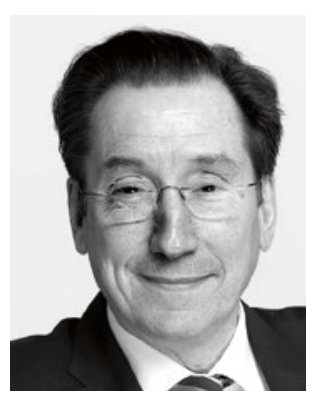

Jürgen Weber
Sicht von Evidence-based Management würde man daher die häufig unreflektierte Praxis hoher Boni im Führungs-Team eines Unternehmens ebenso infrage stellen wie „moderne“ Postulate nach noch mehr Quoten und formalen Regelwerken. Die Umsetzung des Konzepts ist dabei zweifelsohne herausfordernd und nicht immer ohne Abstriche möglich - nicht alles lässt sich rechnen, nicht alles hinreichend validieren und empirisch belegen. Zudem stehen häufig Emotionen und kognitive Verzerrungen einer faktenbasierten analytischen Entscheidungsfindung im Wege. Controller dürfen den damit verbundenen Herausforderungen aber nicht ausweichen, selbst wenn dies bedeutet, dass sie die Komfortzone etablierter Weisheiten, formaler Steuerungsprozesse und eingeschwungener Entscheidungsroutinen gelegentlich verlassen müssen.

Vielleicht kann Ihnen die Auseinandersetzung mit dem seelenverwandten Konzept des Evidence-based Managements ja die eine oder andere Anregung für den Controller-Alltag mit auf den Weg geben. Noch ein Hinweis in eigener Sache: Ab diesem Heft erscheint die Controlling \& Management Review auch als digitales E-Magazin. Nun können Sie uns überall und jederzeit auf mobilen Endgeräten lesen. Sie finden das E-Magazin unter http://emag.springerprofessional.de/cmr. Schnuppern Sie doch mal rein!

Viel Vergnügen bei der Lektüre wünschen Ihnen
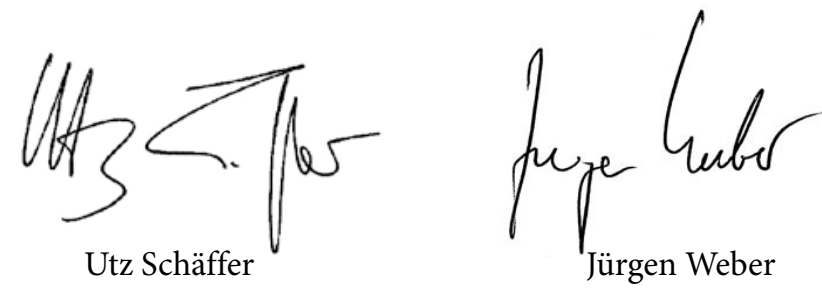